\title{
TL-dating applied to building archaeology: The case of the medieval church Notre-Dame-Sous-Terre (Mont-Saint-Michel, France)
}

\author{
Sophie Blain ${ }^{\mathrm{a}, \mathrm{d}, *}$, Pierre Guibert ${ }^{\mathrm{a}}$, Armel Bouvier ${ }^{\mathrm{a}}$, Emmanuelle Vieillevigne $^{\mathrm{a}}$, Françoise Bechtel ${ }^{\mathrm{a}}$, \\ Christian Sapin ${ }^{\mathrm{b}}$, Maylis Bayléc \\ a IRAMAT-CRP2A-UMR 5060, CNRS-Université de Bordeaux 3, Maison de l'Archéologie, F-33 607 Pessac, France \\ ${ }^{\mathrm{b}}$ Laboratoire Archéologie, Culture et Société-UMR 8894, CNRS-Université de Bourgogne, Dijon, France \\ ${ }^{\mathrm{c}}$ Laboratoire de médiévistique occidentale de Paris, UMR 8589, CNRS-Université de Paris 1, France \\ ${ }^{\mathrm{d}}$ Luminescence Laboratory, Department of Archaeology, University of Durham, South Road, DHI 3LE Durham, UK
}

Received 22 December 2006; received in revised form 27 June 2007; accepted 28 July 2007

\begin{abstract}
The recent application of thermoluminescence (TL) dating to young building materials is being increasingly developed for use in the field of buildings archaeology [Bailif, I.K., Holland, N., 2000. Dating bricks of the two last millennia from Newcastle upon Tyne: a preliminary study. Radiat. Meas. 32, 615-619; Gallo N, Fieni L, Martini M, Sibillia E, 1999. Building archaeology, 14C and thermoluminescence: two examples comparison, Actes du Colloque, "C14 et Archéologie", III ${ }^{e}$ Congrès International, Lyon 6-10 avril 1998, Mémoire de Société préhistorique Française, tome XXVI et Supplément de la revue d'Archéométrie, pp. 425-431; Vieillevigne, E., Guibert, P., Bechtel, F., Leriche, P., 2004. Thermoluminescence et chronologie du bâti médiéval: datation de briques de la citadelle de Termez en Ouzbékistan. Revue d'Archéométrie 28, 43-55.]. Ensuring the accuracy of the dating method is of the utmost importance in order to achieve results which are pertinent enough to have archaeological significance. This paper deals with an archaeological building study of the first church built on the Mont-Saint-Michel (France) and improvements made to the TL-protocol in Bordeaux. The aim is to achieve precise dates for the material under analysis and therefore, a better understanding of the evolution of the building. For this study, 14 bricks have been sampled from eight different masonries and submitted for TL dating analysis. With the exception of one sample which appears to be non-contemporaneous to the others, the date results range from $900 \pm 80$ to $1020 \pm 60 \mathrm{AD}$. The results were then averaged according to the two phases established by the archaeological building study. The first two stages of the primitive church both date from the 10th century.
\end{abstract}

(C) 2007 Elsevier Ltd. All rights reserved.

Keywords: Thermoluminescence dating; Quartz; Brick; Medieval building archaeology

\section{Introduction}

Mont-Saint-Michel is a small, rocky island that lies in a shallow tidal bay between Normandy and Little Brittany in north-western France. In 966, the first official act passed by the Carolingian King Lothaire (954-986) allowed the settlement of

\footnotetext{
* Corresponding author. IRAMAT-CRP2A-UMR 5060, CNRS-Université de Bordeaux 3, Maison de l'Archéologie, F-33 607 Pessac, France.

Tel.: +335571245 53; fax: +33557124550.

E-mail addresses: blain.sophie@gmail.com (S. Blain), guibert@u-bordeaux3.fr (P. Guibert), bouvier_armel@yahoo.fr (A. Bouvier), evieillevign@u-bordeaux3.fr (E. Vieillevigne), sapin.christian@wanadoo.fr (C. Sapin), maylis.bayle@wanadoo.fr (M. Baylé).
}

Benedictine monks on the island with their first abbot, Maynard the 1st (965-991) who is likely to be responsible for the construction of a little church, known as Notre-DameSous-Terre. The building, positioned to the west of the island, was later used as a foundation for subsequent buildings on the upper levels and therefore became underground.

The primitive church is rectangular in shape $(13 \times 11 \mathrm{~m})$. The surrounding wall is punctuated by four windows. A median wall splits the building into two naves, each with small apses at the eastern end (Fig. 1). The whole building is typologically dated to the last third of the 10th century (de Boüard, 1961; Froidevaux, 1961), displaying masonry made up of small granite rectangular carved stones interrupted by rows of brick, flat brick round-headed arches, rectangular pillars with simple 


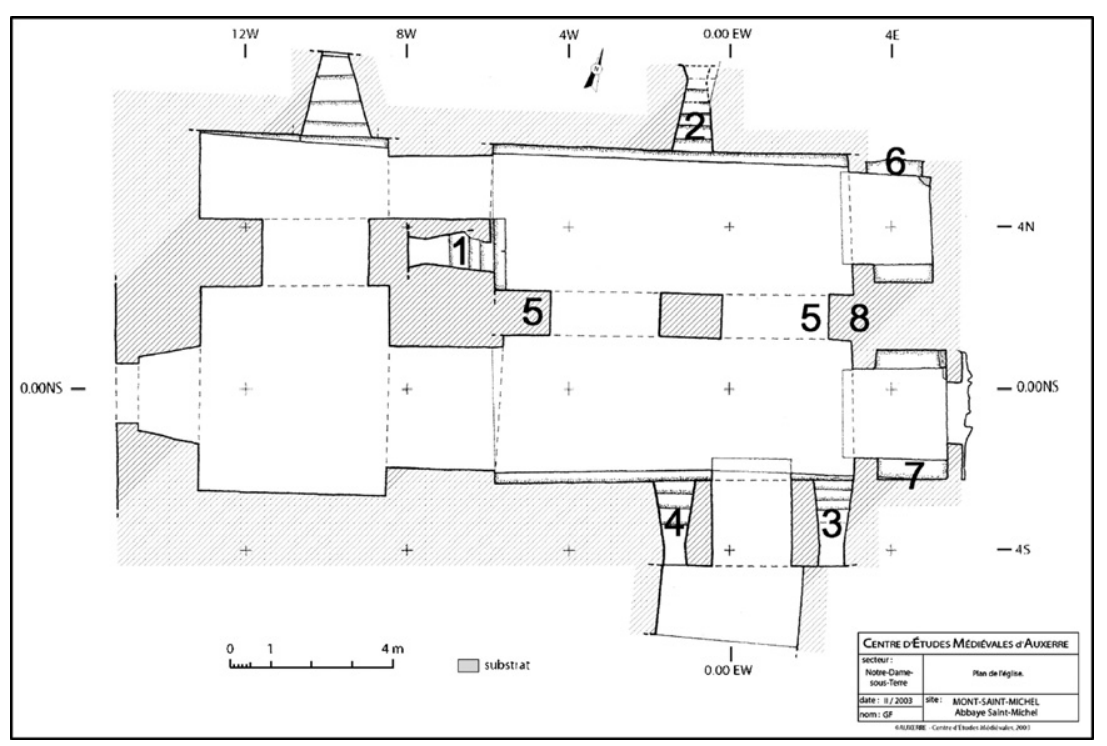

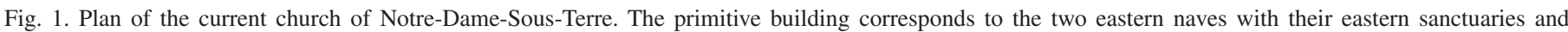

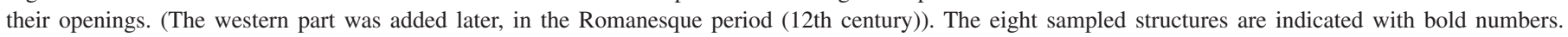

imposts and the absence of an original vault (the vault we see today was added in the 11th century to help support the new building above).

In order not only to check the overall dating, but also to evaluate the phasing of this building and particularly to evaluate the dating of the different phases presupposed from the building archaeological studies (Sapin, 2002), it was decided to combine both historical and archaeological evidence with building material dating (Sapin, 1997) by laboratory-based methods such as thermoluminescence (TL) and archaeomagnetism applied to bricks, and C14 to charcoals from mortar. Another specific area in which TL could particularly provide answers involves the long supposed theory that in medieval times, after the Roman departure, the technical knowledge of brick making disappeared (Baylé, 1997, 2000). Furthermore that, from this period to the 12th century, the brick added to medieval masonry was supposed to have been re-used from Gallo-roman neighbouring sites (de Boüard, 1975). Because the dating method of TL dates the last firing of brick, it can therefore be evaluated whether the bricks used in Notre-Dame-Sous-Terre are medieval or indeed older.

This paper deals with the work carried out on sampled bricks from Notre-Dame-Sous-Terre by the laboratory of luminescence in Bordeaux.

\section{Samples}

The sampling strategy was designed in conjunction with archaeologists according to the historical and archaeological questions to be answered. Eight separate areas of masonry were sampled (Fig. 1), taking 1-4 bricks from each site. Taking multiple samples from each of the selected areas of masonry helps to reduce the effect of anomalous results and, therefore, to achieve a more precise date.

\section{Protocol and experimental aspect}

\subsection{Preliminary studies: the TL of the polymineral fine grains}

A preliminary study was performed on sample Bdx 8851 in order to check for appropriate TL properties of the minerals of the Mont-Saint-Michel bricks. The TL analysis was carried out on polymineral fine grains, generally including feldspars and quartz. A classical (in Bordeaux) determination of the equivalent dose by the additive dose, annealing and regeneration technique (Guibert et al., 1996; Vieillevigne et al., 2006) as well as a fading study was performed. The latter showed that after a storage period of 2 weeks, the TL signals tends to fade slightly, with a reduction in signal strength of ca. 5\% occurring after 43 days storage (the total sample analysis time). This fading tendency may potentially introduce large errors in the total age determination and the level in inaccuracy due to this fading effect was further highlighted by the subsequent determination of the equivalent dose (fine grain); despite high intensity signals and reproducible results, the age obtained after the preliminary study was inconsistent with historical and archaeological data: $1195 \pm 40 \mathrm{AD}$ for a building that is known historically to have been built before the Romanesque abbey (1023 AD). We decided not to use polymineral grains but quartz as chronological vector to effectively reduce inaccuracies due to fading risks.

\subsection{Selection of quartz minerals}

The equivalent dose was determined from quartz crystals, using either coarse or fine grains.

Coarse grains of quartz $(80-200 \mu \mathrm{m})$ were extracted and chemically etched following a three-stage procedure: (i) $\mathrm{HCl} 1 \mathrm{M}$ to dissolve carbonate minerals, (ii) $\mathrm{H}_{2} \mathrm{O}_{2} 50 \mathrm{vol}$ to 


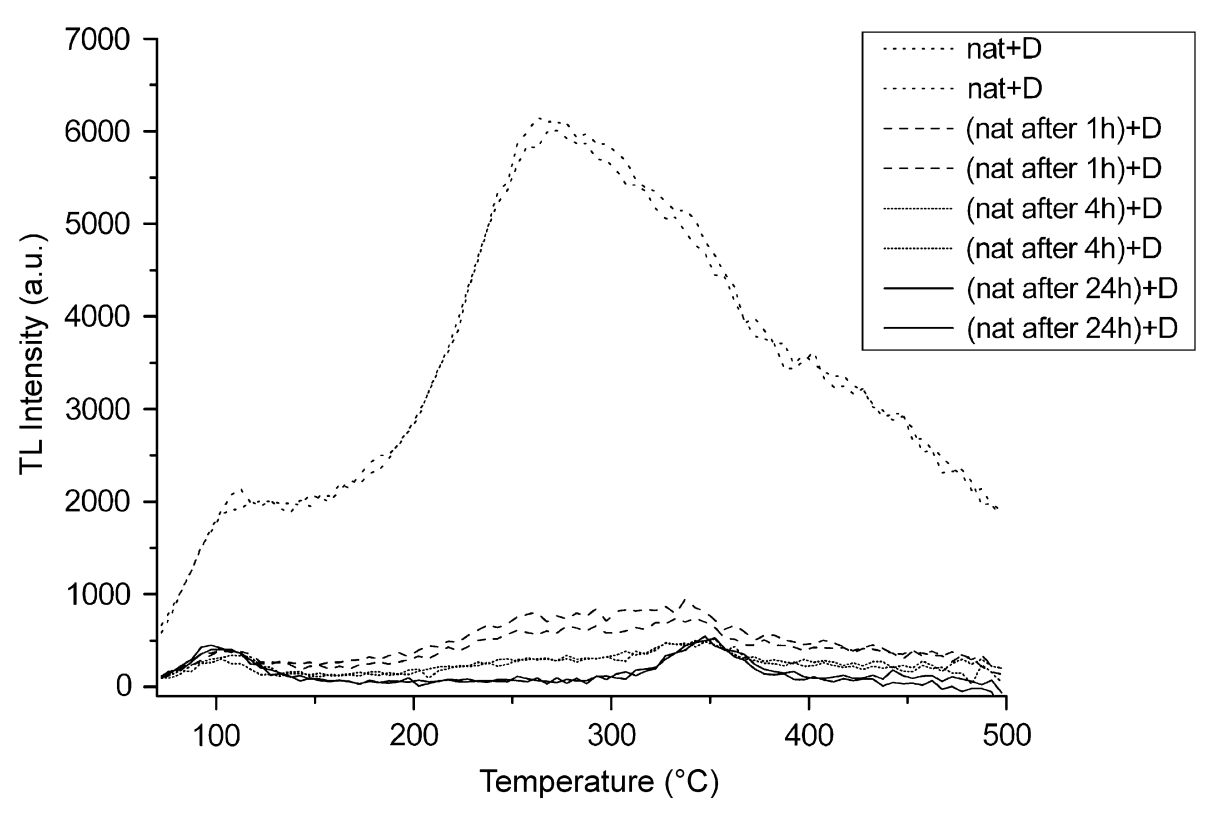

Fig. 2. Evolution of the TL curves without $\mathrm{H}_{2} \mathrm{SiF}_{6}$ etching and after 1,4 , and $24 \mathrm{~h}$ etching.

remove organic material, and (iii) $\mathrm{H}_{2} \mathrm{SiF}_{6}(31 \%)$ for repeated $72 \mathrm{~h}$ cycles ( 2 to 3 times) to eliminate feldspars. The etching efficiency was monitored using cathodoluminescence with small aliquots: when not totally removed, the presence of remaining $\mathrm{K}$ feldspars is detected by their localised light blue luminescence signal. It should be noted that we decided not to use the HF etching procedure that is usually employed to remove the external layer of grains and hence the external alpha-dose contribution; it is known that HF etching is not isotropic and efficient in the complete removal of the outer $20 \mu \mathrm{m}$ layer of the quartz grains. Subsequently, a heavy liquid separation was carried out on the paleodose deriving grains in order to remove the potential remaining feldspars and heavy minerals such as zircon, titanium oxides.

Fine grains of quartz were also chemically selected from the less than $40 \mu \mathrm{m}$ fraction using the same method as the coarse grains, with the exception of the heavy liquid separation stage. Grains measuring 3-12 $\mu \mathrm{m}$ were selected by sedimentation. As an example, Fig. 2 illustrates the efficiency of $\mathrm{H}_{2} \mathrm{SiF}_{6}$ pretreatment on fine grains of quartz after various durations of etching (1, 4 and $24 \mathrm{~h})$. The TL curves related to the non-etched material showed very intense signals, with the characteristic shapes associated with feldspar derived signals, particularly in the higher temperature range $\left(200-500^{\circ} \mathrm{C}\right)$; a reduction in the observed intensity of the $110^{\circ} \mathrm{C}$ quartz peak was noted. After various $\mathrm{H}_{2} \mathrm{SiF}_{6}$ etching times, the signal intensity decreased gradually (to one-tenth). Over time, the 110 and $350{ }^{\circ} \mathrm{C}$ peaks, characteristic of quartz, were increasingly defined.

The presence of feldspars, indicated by the TL observations, was also confirmed analytically using cathodoluminescence. Small representative aliquots of etched fine grains were routinely sampled and characterised using cathodoluminescence to evaluate qualitatively, the presence of remaining feldspars.
Further etching was performed if the presence of remaining feldspars was confirmed.

\subsection{Determination of $D_{\mathrm{e}}$ by $T L$}

As mentioned previously, the equivalent dose was evaluated by an additive dose and regeneration procedure (Guibert et al., 1996) using quartz crystals. Regardless of grain size, two separate sets of naturally irradiated quartz are used in the $D_{\mathrm{e}}$ determination; in case of quartz inclusion dating, determination of the alpha efficiency is required.

Following the Bordeaux standard TL-dating process, two series of TL measurements are required. The first series ("first TL reading') is performed on aliquots from the first set of quartz minerals. Some aliquots are irradiated with an additional laboratory dose. After the initial TL readings, the regenerative growth characteristics of the TL signals are determined. As the determination of the regeneration characteristics in response to lower doses (than the natural) is also necessary, a second series of TL measurements is required. These tests are performed on previously annealed aliquots from the second set, which must be distinct from the first (Fig. 3). After artificial irradiation and subsequent TL readings, the regenerative dose characteristics can be studied, and finally the $D_{\mathrm{e}}$ can be determined. Routinely, a non-linear fit is deduced from the second readings, and then the corresponding function is applied to the experimental data points of the first series, according to a scaling method that takes into account differences in sensitivity or mass between first and second readings aliquots (Guibert et al., 1996).

$\mathrm{H}_{2} \mathrm{SiF}_{6}$ etching procedures are known not to completely remove the external surface of the grains and checking has been made with BSE-SEM: the shape of the quartz grains after $\mathrm{H}_{2} \mathrm{SiF}_{6}$ still have angular faceting, rather than the smoothed 


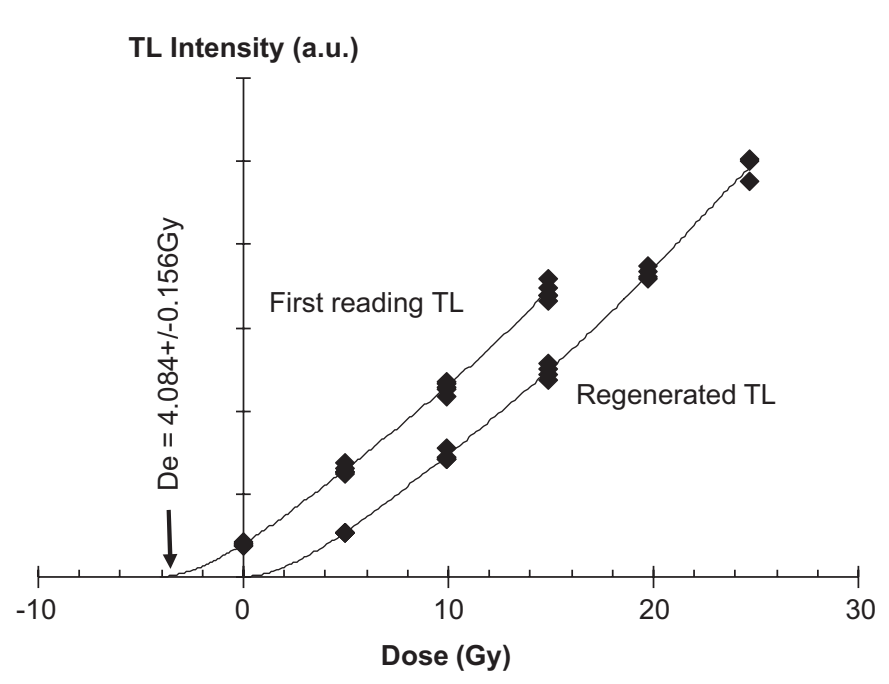

Fig. 3. First- and second-glow growths of the sample Bdx 8862.

surfaces expected after efficient etching. Consequently, it is necessary to determine the $\alpha$ dose contribution to the $D_{\mathrm{e}}$. The $k$-value determination is carried out on fine grains. To calculate the $k$-value appropriate to coarse grains, the material must be crushed initially to a size appropriate to this determination, i.e. a particle size less than the alpha range in quartz (Aitken, 1985).

Coarse natural grains from a third set of original grains are first crushed to a diameter less than $40 \mu \mathrm{m}$ and heated in order to remove natural TL signals and to reduce those induced by grinding. The $3-12 \mu \mathrm{m}$ fraction is then separated by sedimentation, and the resulting grains deposited onto identical brass discs (ca. $1 \mathrm{mg}$ per aliquot) by a further sedimentation process. Some aliquots of the annealed material are given an alpha dose equal to ca. ten times the beta $D_{\text {e }}$ already determined. Others are given increasing beta doses that define a growth curve (TL intensity versus beta dose); $\alpha-D_{\mathrm{e}}$ is deduced from the intersection of TL intensity of alpha-dosed aliquots, with the $\beta$ dose growth curve. $k$-value is then known.

In the case of quartz fine grain dating protocol, additional aliquots of the annealed material are alpha irradiated and the relative alpha efficiency is deduced from a direct comparison of TL intensities between alpha irradiated aliquots and those used for the second reading experiments that are beta irradiated.

All aliquots are given a three step luminescence reading: after irradiation (natural or artificial beta or alpha), (i) first heating, followed by (ii) a second heating to measure the background, and (iii) irradiation by a beta test dose and third heating to normalize intensities.

The TL is recorded with an automated TL-reader built in CRP2A (Guibert, 2002), according to the following conditions: heating to $500{ }^{\circ} \mathrm{C}$ at $4{ }^{\circ} \mathrm{C} / \mathrm{s}$ in wet nitrogen atmosphere $(96 \%$ $\mathrm{N}_{2}, 4 \% \mathrm{H}_{2} \mathrm{O}$ vapour), preheat at $190^{\circ} \mathrm{C}$ for $2 \mathrm{~min}$, spectral window from 350 to $450 \mathrm{~nm}$ (2 Schott BG12 and IR rejector optical filters; phototube EMI 9813 QA). Laboratory irradiations are given by a ${ }^{90} \mathrm{Sr}-{ }^{90} \mathrm{Y}$ beta source delivering ca. $0.075 \mathrm{~Gy} / \mathrm{s}$
$( \pm 1.5 \%)$ and $\mathrm{a}^{241} \mathrm{Am}$ alpha source delivering $0.21 \mathrm{~Gy} / \mathrm{s}( \pm 5 \%)$ in silica.

\section{4. 'Annealing test' and determination of annealing conditions}

As described above, prior to the second TL reading, annealing is required; this is achieved by a one-hour heating at a temperature to be determined. The selection of this temperature is essential because of the effects of the heating on the behaviour of the material. Indeed, changes in luminescence properties of quartz are induced by thermal treatment (Roque et al., 2004), and the $D_{\mathrm{e}}$ values measured can vary widely with annealing temperature as a result of changes in the growth curve shape. It is then necessary to determine a temperature that could lead to an electronic state of the material equivalent to the one due to its archaeological heating. In practice, the choice of the 'equivalent temperature' is related to the annealing temperature that generates, by laboratory irradiation, glow curves that best fit the natural or the natural + dose curves.

In practice, the $40-80 \mu \mathrm{m}$ grain size quartz fraction is generally used to determine the more appropriate annealing temperature. The regenerated TL signals of quartz annealed at different temperature from 500 to $800^{\circ} \mathrm{C}$ are studied (and, in some cases, at lower temperatures), in comparison with natural (and beta dose added) TL signals on the same grain size minerals. The aim is to investigate possible changes in TL sensitivity and changes in the glow curve shapes that could be used to evaluate the temperature of an annealing cycle that approaches the archaeological firing. The glow curves are compared to the natural/natural+dose ones according to two main TL emissions: one for the low-temperature components including the $110^{\circ} \mathrm{C}$ peak, and the other one that includes the high-temperature region (in the range of $280-480^{\circ} \mathrm{C}$ ). Moreover, differences in glow curve shapes occur between different samples according to the origin of the quartz crystals and the thermal history of the brick, and the changes induced by thermal treatment need to be investigated for each sample in order to obtain clues about heating conditions equivalent to the archaeological ones.

Finally, the later plateau-test is an a posteriori check. Depending on its shape, we can evaluate whether the choice of the annealing temperature was justified. For instance, a doseplateau showing an increasing gradient will generally mean that the sample has been annealed with too high a temperature. That behaviour was observed in poorly heated Palaeolithic quartz pebbles (Roque et al., 2004).

\subsection{Annual dose evaluation}

Internal annual doses of bricks were determined from low-background gamma spectrometry measurements (Guibert and Schvoerer, 1991; Fai“n et al., 1997) of powdered brick samples. Note that for each brick, the material used for TL measures and gamma spectrometry ones came from the same original sample, in order to avoid possible local heterogeneity effects from a same brick. First, radioelement concentrations 
were determined, and then converted into the corresponding annual doses using Adamiec and Aitken's data (1998). All samples were analysed with a well low-background high-purity Ge detector (Canberra-Eurisys Mesures, EGPC 200 P17) capable of detecting natural gamma rays with high efficiency and with small amounts of material (around $8 \mathrm{~g}$ ).

The gamma and cosmic dose rates have been calculated from in situ dosimetry using $\mathrm{CaSO}_{4}$ :Tm powder. The dosimeters were placed at the exact sampling location in masonries. Additional on site measurements of the environmental dose-rate during the sampling campaign, using a portable $\gamma$-ray spectrometer (NaI:Tl $2^{\prime} \times 2^{\prime}$, Canberra NaI Inspector) were carried out.

Alpha and beta dose rates were evaluated using radioactivity measurements of bricks and annual dose factors reported by Adamiec and Aitken (1998). Their respective attenuation factors in coarse grains (the $\alpha$ contribution is not neglected because of the use of $\mathrm{H}_{2} \mathrm{~F}_{6} \mathrm{Si}$ which does not remove the external surface of grains) were calculated using data published by Brennan et al. (1991) and Mejdahl (1979). Furthermore, the coarse grain fraction used in TL measurements was subdivided by grain size range and weighed giving the respective mass proportion of grains of the following sizes: 80-100, 100-125, 125-160 and $160-200 \mu \mathrm{m}$ in order to evaluate, with an optimised precision, the corresponding attenuation factors, assuming a uniform TL sensitivity whatever the grain size.

An arbitrary value of $5 \pm 3 \%$ was assigned to the moisture content of bricks, due to the consideration of the location of the sample, i.e. in an underground building not submitted to capillary effects and protected by buildings above from water flow. The topographical situation of the Notre-Dame-sous-Terre church has effectively contributed to what may be assumed as a notionally dry environment for the bricks. The site is now open to visitors and the contemporary moisture content remained negligible.

\section{Results and discussion}

\subsection{TL study}

Table 1 shows the annealing temperatures, the $D_{\mathrm{e}}$ measurement results and the $k$-value for each sample. Uncertainties associated with $D_{\mathrm{e}}$ and $k$-values are statistical ones that are related to the dispersion of TL intensities between aliquots. The $D_{\mathrm{e}}$ values for the 14 samples vary from $4.08 \pm 0.16$ to $5.90 \pm 0.32 \mathrm{~Gy}$. Annealing temperatures range between 600 and $700{ }^{\circ} \mathrm{C}$, except $\mathrm{Bdx} 8857$, which was under-fired, and has an annealing temperature evaluated to be $360^{\circ} \mathrm{C}$.

In coarse grains, we noticed that the $\alpha$ contribution, which is taken into account, is surprisingly very low (Table 1). Moreover, it was noted that for some samples, this small $k$-value evolves with temperature (Fig. 4). With $\beta$ or $\alpha$ irradiation, the shape of TL curves varies, especially at high temperatures where the material appears to be increasingly sensitive to the $\alpha$ radiation. A simultaneous decrease in beta sensitivity was also noted. Then the variability of $k$ is also dependent upon the integration range (the temperature range within the TL counts are summed).

\subsection{Annual dose}

$\mathrm{K}$, U, and Th contents are reported in Table 2. Although the Th and K contents (Fig. 5) appear to group together, they are actually quite spread, especially Bdx 8851, which deviates from this grouping. This absence of a general, discernable tendency is probably due to an intrinsic variability in the raw material or localised isotopic heterogeneity in bricks.

U-series are in quasi equilibrium (ca. 10\%) except for the sample Bdx 8863, which substantially deviates from the main pattern (Fig. 5). The origin of this slight disequilibrium is not obvious. Different models explaining the disequilibrium can be considered (Guibert et al., 1997; Roque et al., 2002) as far as gamma spectrometry cannot indicate by itself its exact origin, since the ${ }^{230} \mathrm{Th}$ gamma line at $67.7 \mathrm{keV}$ is not routinely visible with the equipment used. The examination of the distribution of points that belong to the main sequence of samples (all except Bdx 8863), does not permit us to clearly determine either $U$ or Ra content changed (Fig. 5), since they exhibit both a relative variability, as a possible consequence of the intrinsic variability of the raw material. Apart from outlying sample $\mathrm{Bdx} 8863$, the uncertainties regarding the mechanism disequilibrium are of little dosimetric consequence. So, in contrast, the outlier sample, with a noticeable high $\mathrm{U}$ content, tends to demonstrate that change in uranium concentration is a likely phenomenon there, at least for one sample.

For this study, we finally choose to consider the behaviour of the group of bricks as a whole and concluded that the system is best reflected by $\mathrm{U}\left({ }^{238} \mathrm{U},{ }^{235} \mathrm{U},{ }^{234} \mathrm{U}\right)$ variations than by ${ }^{226} \mathrm{Ra}$ ones. Therefore, the annual dose in the brick would have been constant if we assume that movement of radionuclides, particularly uranium, within these materials is limited, due particularly to the absence of moisture. Potentially, disequilibrium may have occurred in the raw material before manufacture. The particular case of $\mathrm{Bdx} 8863$ could result from subsequent enrichment of uranium from dripping water, maybe due to it's location in the church, i.e. near the granite block shrine of the primitive Christian settlement. This is still to be confirmed by additional analyses of the mortar embedding that the brick may have absorbed mobile uranium. Adamiec and Aitken's conversion data (1998) were modified to take account of disequilibrium and calculate an adjusted U-series contribution to the internal dose rate.

Annual gamma dose rate was evaluated by in situ dosimetry $\left(\mathrm{CaSO}_{4}: \mathrm{Tm}\right)$ and gamma spectrometry, measured with a portable NaI:Tl spectrometer. The gamma spectrometry values were generally smaller than the in situ dosimetry ones. This is assumed to be the result of a geometry effect-probably due to the relatively small size of the dosimeter capsules in relation to the spectrometer probe, and the relative proximity of the capsules and spectrometer probe to the building surfaces.

In fact the spectrometer results represent a smoothed average of the local dosimetric values. We therefore decided to use the local dosimetry results to complete the annual dose rate determination (Table 3). 
Table 1

Equivalent dose values and statistical standard deviations determined from TL experiments

\begin{tabular}{|c|c|c|c|c|c|c|}
\hline Reference on the plan & Masonry & Sample & Technique & Annealing temperature $\left({ }^{\circ} \mathrm{C}\right)$ & $k$ & $D_{\mathrm{e}}(\mathrm{Gy})$ \\
\hline 1 & Window W & Bdx 8854 & Fine grains & 700 & $0.029 \pm 0.001$ & $4.26 \pm 0.39$ \\
\hline 2 & Window N & Bdx 8866 & Coarse grains & 600 & $0.025 \pm 0.001$ & $4.14 \pm 0.31$ \\
\hline 3 & Window SE & Bdx 8861 & Coarse grains & 600 & $0.055 \pm 0.004$ & $4.29 \pm 0.29$ \\
\hline \multirow{2}{*}{4} & \multirow{2}{*}{ Window S } & & Coarse grains & 700 & $0.066 \pm 0.003$ & $4.24 \pm 0.39$ \\
\hline & & Bdx 8859 & Coarse grains & 600 & $0.096 \pm 0.006$ & $4.99 \pm 0.69$ \\
\hline \multirow[t]{2}{*}{5} & \multirow[t]{2}{*}{ Median wall } & Bdx 8851 & Fine grains & 750 & $0.050 \pm 0.002$ & $4.89 \pm 0.33$ \\
\hline & & Bdx 8857 & Fine grains & 360 & $0.019 \pm 0.001$ & $5.71 \pm 0.40$ \\
\hline 6 & Apse $\mathrm{N}$ & Bdx 8864 & Coarse grains & 600 & $0.035 \pm 0.001$ & $4.23 \pm 0.30$ \\
\hline
\end{tabular}

The systematic error relevant to the source calibration is $2 \%$ for $\beta D_{\mathrm{e}}$. Annealing temperatures are indicated for any dated brick. The technique used is precised for each sample.
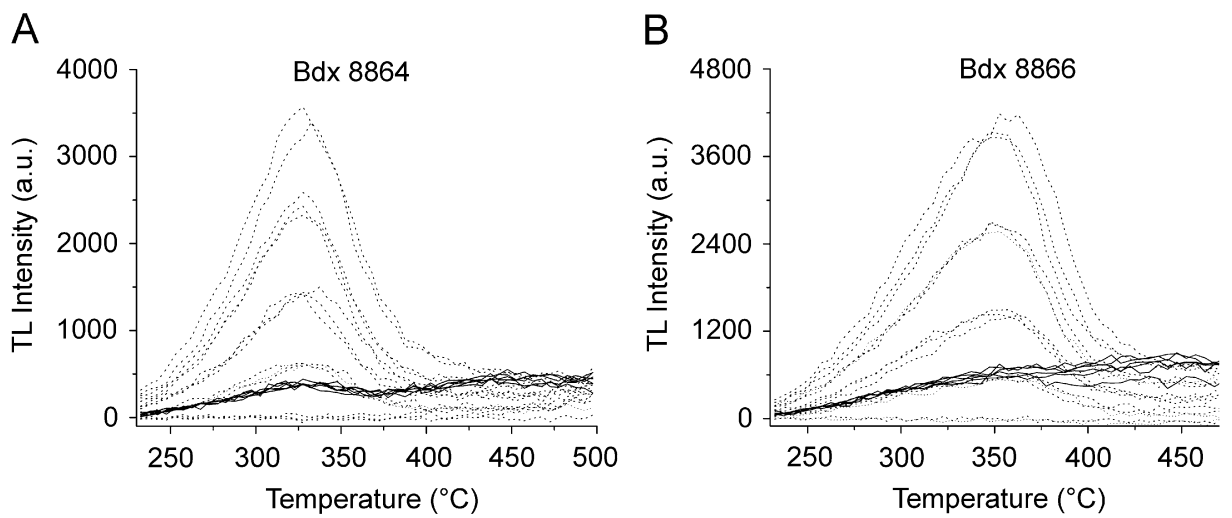

Fig. 4. TL curves from 3-12 $\mu \mathrm{m}$ fraction derived from crushed and annealed coarse grains of samples Bdx 8864 (A) and Bdx 8866 (B) and irradiated with increasing added beta doses and alpha doses (bold curves), used for $k$-value evaluation.

Table 2

Radiochemical composition of bricks to be dated, determined by low background gamma spectrometry

\begin{tabular}{lllll}
\hline Sample & $\mathrm{K}(\%)$ & $\mathrm{U}\left({ }^{238} \mathrm{U}\right)(\mathrm{ppm})$ & $\mathrm{U}\left({ }^{226} \mathrm{Ra}\right)(\mathrm{ppm})$ & $\mathrm{Th}(\mathrm{ppm})$ \\
\hline Bdx 8853 & $2.59 \pm 0.04$ & $3.79 \pm 0.17$ & $4.17 \pm 0.04$ & $11.11 \pm 0.13$ \\
Bdx 8854 & $2.28 \pm 0.03$ & $3.47 \pm 0.20$ & $3.96 \pm 0.04$ & $12.22 \pm 0.14$ \\
Bdx 8856 & $2.59 \pm 0.03$ & $3.19 \pm 0.18$ & $2.53 \pm 0.03$ & $12.43 \pm 0.13$ \\
Bdx 8866 & $2.49 \pm 0.04$ & $3.23 \pm 0.17$ & $4.03 \pm 0.05$ & $12.87 \pm 0.15$ \\
Bdx 8861 & $2.61 \pm 0.13$ & $3.53 \pm 0.13$ & $4.28 \pm 0.04$ & $14.45 \pm 0.12$ \\
Bdx 8862 & $2.52 \pm 0.03$ & $3.45 \pm 0.16$ & $4.13 \pm 0.04$ & $14.37 \pm 0.15$ \\
Bdx 8858 & $2.80 \pm 0.04$ & $2.87 \pm 0.15$ & $3.36 \pm 0.04$ & $3.55 \pm 0.04$ \\
Bdx 8859 & $2.84 \pm 0.04$ & $3.61 \pm 0.21$ & $5.20 \pm 0.25$ & $14.16 \pm 0.14$ \\
Bdx 8851 & $3.05 \pm 0.04$ & $5.93 \pm 0.06$ & $4.44 \pm 0.05$ & $14.67 \pm 0.19$ \\
Bdx 8857 & $3.58 \pm 0.05$ & $3.60 \pm 0.21$ & $5.42 \pm 0.05$ & $14.33 \pm 0.17$ \\
Bdx 8864 & $2.86 \pm 0.04$ & $4.06 \pm 0.15$ & $6.07 \pm 0.05$ & $13.12 \pm 0.12$ \\
Bdx 8865 & $3.01 \pm 0.04$ & $4.72 \pm 0.15$ & $4.33 \pm 0.04$ & $13.89 \pm 0.13$ \\
Bdx 8863 & $2.88 \pm 0.04$ & $8.17 \pm 0.20$ & $3.79 \pm 0.04$ & $14.53 \pm 0.14$ \\
Bdx 8860 & $3.06 \pm 0.04$ & $3.47 \pm 0.16$ & &
\end{tabular}

Uranium, thorium and potassium concentration are with their statistical error. 
A

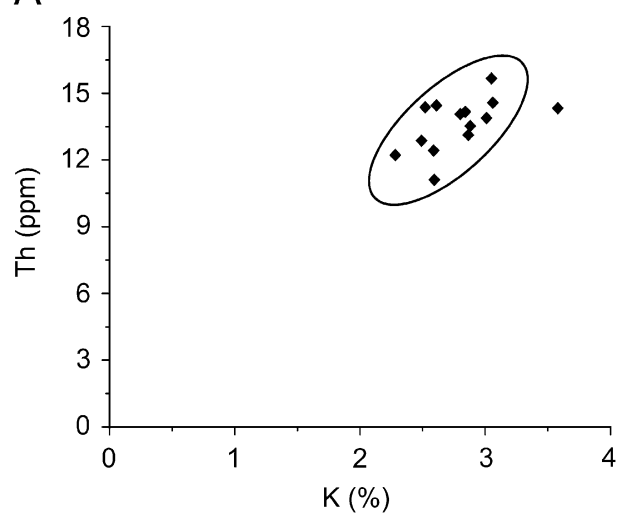

B

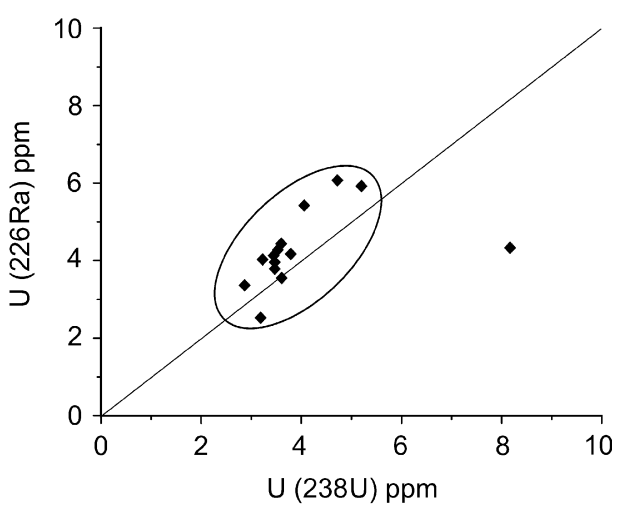

Fig. 5. Th and K contents (A) and equilibrium state of the U-series (B) in bricks from Notre-Dame-sous-Terre (Mont Saint Michel, France).

Table 3

Dose rates determinations of the bricks of Notre-Dame-Sous-Terre under study

\begin{tabular}{|c|c|c|c|c|}
\hline Sample & $\alpha$ dose rate $(\mathrm{mGy} / \mathrm{yr})$ & $\beta$ dose rate $(\mathrm{mGy} / \mathrm{yr})$ & Environmental dose rate (mGy/yr) & Total dose rate (mGy/yr) \\
\hline Bdx 8853 & $0.07 \pm 0.01$ & $2.54 \pm 0.09$ & $1.41 \pm 0.05$ & $4.02 \pm 0.15$ \\
\hline Bdx 8854 & $0.53 \pm 0.02$ & $2.50 \pm 0.09$ & $1.41 \pm 0.05$ & $4.45 \pm 0.16$ \\
\hline Bdx 8856 & $0.40 \pm 0.02$ & $2.60 \pm 0.09$ & $1.37 \pm 0.05$ & $4.37 \pm 0.16$ \\
\hline Bdx 8866 & $0.06 \pm 0.01$ & $2.46 \pm 0.08$ & $1.36 \pm 0.05$ & $3.88 \pm 0.15$ \\
\hline Bdx 8861 & $0.15 \pm 0.01$ & $2.61 \pm 0.13$ & $1.29 \pm 0.04$ & $4.05 \pm 0.18$ \\
\hline Bdx 8862 & $0.09 \pm 0.01$ & $2.53 \pm 0.09$ & $1.29 \pm 0.04$ & $3.91 \pm 0.15$ \\
\hline Bdx 8858 (fine grains) & $0.82 \pm 0.07$ & $2.85 \pm 0.10$ & $1.31 \pm 0.04$ & $4.98 \pm 0.20$ \\
\hline Bdx 8858 (coarse grains) & $0.16 \pm 0.01$ & $2.64 \pm 0.09$ & $1.31 \pm 0.04$ & $4.10 \pm 0.15$ \\
\hline Bdx 8859 & $0.23 \pm 0.02$ & $2.72 \pm 0.09$ & $1.31 \pm 0.04$ & $4.26 \pm 0.16$ \\
\hline Bdx 8851 & $0.17 \pm 0.04$ & $3.18 \pm 0.10$ & $1.49 \pm 0.07$ & $4.85 \pm 0.26$ \\
\hline Bdx 8857 & $0.40 \pm 0.02$ & $3.56 \pm 0.12$ & $1.49 \pm 0.04$ & $5.46 \pm 0.21$ \\
\hline Bdx 8864 & $0.10 \pm 0.01$ & $2.87 \pm 0.10$ & $1.47 \pm 0.05$ & $4.45 \pm 0.17$ \\
\hline Bdx 8865 & $0.18 \pm 0.01$ & $3.07 \pm 0.10$ & $1.47 \pm 0.05$ & $4.72 \pm 0.18$ \\
\hline Bdx 8863 & $0.18 \pm 0.01$ & $3.00 \pm 0.10$ & $1.24 \pm 0.04$ & $4.35 \pm 0.17$ \\
\hline Bdx 8860 & $0.16 \pm 0.01$ & $2.89 \pm 0.10$ & $1.52 \pm 0.04$ & $4.57 \pm 0.17$ \\
\hline
\end{tabular}

Uncertainties are one standard deviation. They include statistical and systematic components.

\subsection{Dates}

Table 4 regroups, respectively, the individual TL-dating results and those shown per location (phases presupposed archaeologically and masonry). Overall and statistical uncertainties $(1 \sigma)$ are reported.

The uncertainties from measurements are of two kinds:

(i) Statistical uncertainties are the random error due to the dispersion of independent measurements. They concern uncertainties of counting in gamma spectrometry and of $D_{\mathrm{e}}$ measurements (due to the dispersion of the TL curves).

(ii) Systematic uncertainties associated all the quantities used in the age calculation. They are mainly related to the gamma spectrometry calibration, to the radioactive sources calibration and to the water content.

All uncertainties are quadratically summed in order to determine the overall uncertainty for each sample.
The dating of several samples for a single archaeological structure allows the evaluation of the convergence of measurements. Taking multiple samples increases the significance of the chronological approach and appears to be essential in TL where the evaluation of only the quantifiable statistical and systematic uncertainties could be insufficient.

Except for sample Bdx 8860, the grouping of TL ages for the overall building is consistent with the expected dispersion of results given by statistical uncertainties. Therefore ages have been averaged using a classical procedure: the weighting coefficient that affects every TL-age is proportional to the inverse of statistical variance (C.E.A., 1975).

The result obtained from the single brick Bdx 8860 located on the second floor presents an older date than the rest. By applying the statistical $\chi^{2}$ test we concluded that this result appears to be inconsistent compared to the others considering their contemporaneity. Fig. 6 shows the $d_{i}$ value with $d_{i}=\left(A_{i}-\right.$ $\left.A_{m}\right) / \sigma_{i}$ stat where $A_{i}$ is the age (yrs) of the sample $i, \sigma_{i}$ stat the statistical uncertainty related to this value and $A_{m}$, the mean 
Table 4

Final weighted average dates and relevant uncertainties are reported for each sample, each masonry and each phase

\begin{tabular}{|c|c|c|c|c|c|c|c|c|}
\hline $\begin{array}{l}\text { Brick } \\
\text { sample }\end{array}$ & $\begin{array}{l}\text { Dates(AD) } \\
\pm 1 \sigma_{\text {total }}(\mathrm{yrs})\end{array}$ & $\begin{array}{l}\text { Stat. std. } \\
\text { dev. (yrs) }\end{array}$ & Masonry & $\begin{array}{l}\text { Dates(AD) } \\
\pm 1 \sigma_{\text {total }}(\mathrm{yrs})\end{array}$ & $\begin{array}{l}\text { Stat. std. } \\
\text { dev. (yrs) }\end{array}$ & Phase & $\begin{array}{l}\text { Dates(AD) } \\
\pm 1 \sigma_{\text {total }}(\mathrm{yrs})\end{array}$ & $\begin{array}{l}\text { Stat. std. } \\
\text { dev. (yrs) }\end{array}$ \\
\hline $\mathrm{Bdx} 8853$ & $947 \pm 131$ & 125 & Window W & $985 \pm 68$ & 56 & 1 & $952 \pm 47$ & 26 \\
\hline $\mathrm{Bdx} 8854$ & $1049 \pm 93$ & 86 & & & & & & \\
\hline Bdx 8856 & $947 \pm 100$ & 92 & & & & & & \\
\hline $\mathrm{Bdx} 8866$ & $941 \pm 89$ & 79 & Window N & $941 \pm 89$ & 79 & & & \\
\hline Bdx8861 & $946 \pm 85$ & 76 & Window SE & $958 \pm 52$ & 36 & & & \\
\hline $\mathrm{Bdx} 8862$ & $962 \pm 75$ & 41 & & & & & & \\
\hline $\begin{array}{l}\text { Bdx8858 } \\
\text { (combined } \\
\text { date) }\end{array}$ & $916 \pm 86$ & 76 & Window S & $899 \pm 80$ & 69 & & & \\
\hline Bdx8859 & $832 \pm 168$ & 162 & & & & & & \\
\hline Bdx 8864 & $1054 \pm 75$ & 67 & Apse N & $1021 \pm 62$ & 50 & 2 & $986 \pm 48$ & 31 \\
\hline $\mathrm{Bdx} 8865$ & $985 \pm 85$ & 76 & & & & & & \\
\hline $\mathrm{Bdx} 8863$ & $954 \pm 75$ & 64 & Apse S & $954 \pm 75$ & 64 & & & \\
\hline Bdx8851 & $994 \pm 75$ & 68 & Median wall & $977 \pm 61$ & 50 & & & \\
\hline Bdx 8857 & $958 \pm 82$ & 73 & & & & & & \\
\hline Bdx 8860 & $716 \pm 84$ & 70 & Upper Gallery & $716 \pm 84$ & 70 & $?$ & & \\
\hline
\end{tabular}

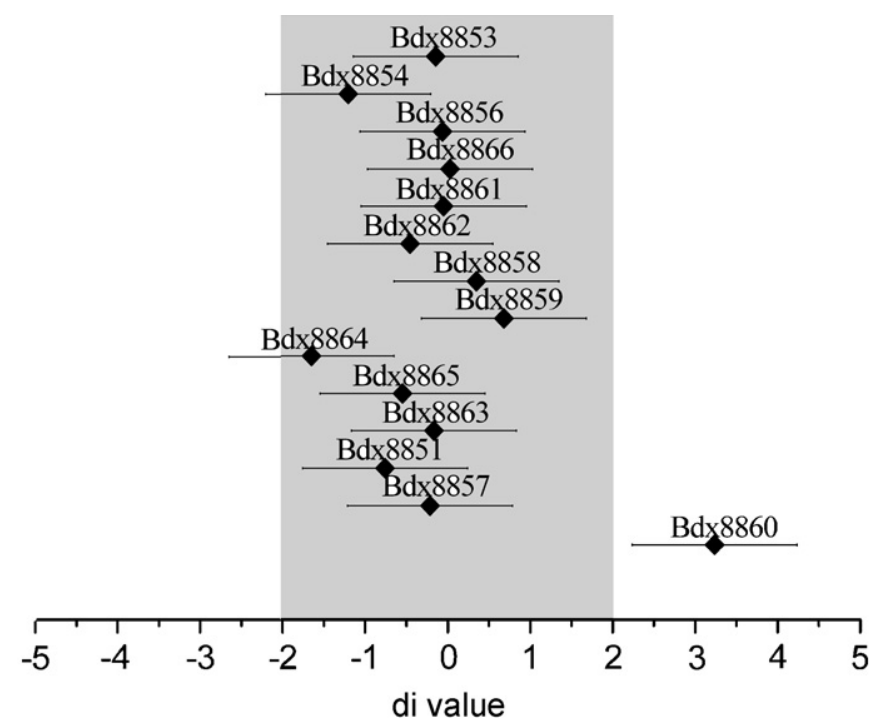

Fig. 6. Distances between individual ages and their mean value $\left(d_{i}=\left(A_{i}-A_{m}\right) / \sigma_{i}\right.$ stat $)$, expressed in terms of number of statistical standard deviations. All dates, except Bdx 8860, are normally distributed (within the $[-2,2]$ interval). Bdx 8860 is supposed to have been reused from an older monument.

age (yrs). It can be seen that sample Bdx 8860 presents the only result outside the range $[-2 ;+2]$. This being the case, we decided not to include it in the overall dating. With a date result of $716 \pm 84 \mathrm{AD}$, it might be interpreted as a re-used brick from a previous settlement on the island.

Although the interval of these individual dates shows no discernable gaps that could indicate different phases in the construction (Fig. 7), by averaging the results and working with archaeological evidence, we can calculate the averaged dates of the phases of construction assuming that the manufacturing of bricks is contemporary to the edification. The final dates are

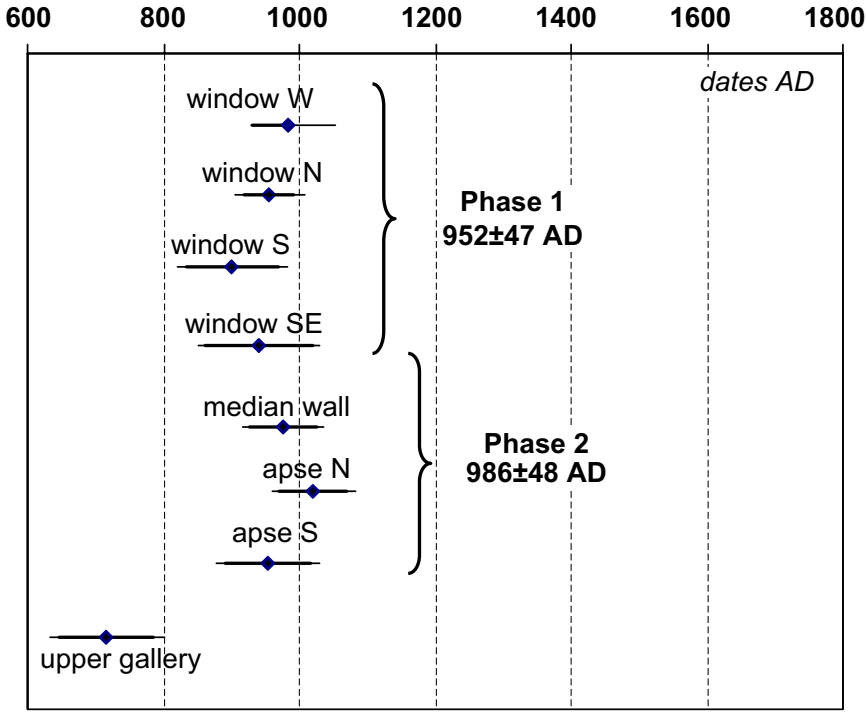

Fig. 7. Averaged dating results for masonries and building phases from the church Notre-Dame-Sous-Terre.

reported in Table 4. By applying a truncated Gaussian curve based on the combination of the physical measurement results and the archaeological constraint (the phase 2 is posterior to the phase 1), the phases appear to be separated by less than 60 years at $68 \%$ level of confidence; less than 104 years at a $95 \%$ level of confidence. These final results are therefore, in good agreement with the archaeological and historical interpretations.

\section{Conclusion}

The 14 individual dates have been averaged first by structure, then by phase, in order to improve the precision and the accuracy of the phasing dating. The final results, except the likely reused brick in the upper gallery, show that the two 
archaeologically separated phases appear to be slightly successive. The first one corresponds to the square surrounding wall of the primitive building which was probably built with the arrival of the bishop Maynard I (965 AD). Then, probably a couple of decades later, the building was carried on by adding the eastern sanctuaries and the median wall.

In order to avoid fading due to the presence of feldspars in polymineral powder, the only mineral section selected was quartz. This was achieved by a preferential chemical etching, using $\mathrm{H}_{2} \mathrm{SiF}_{6}$. Although this methodological innovation provided a solution to the problem of long-term fading, the results obtained from quartz were more spread than those obtained with the fine grain technique. This can be explained by the intrinsic variability of quartz and its lower sensitivity, which is smoothed by the presence of feldspars in the polymineral technique.

In order to date masonries, several bricks from each structure under analysis have been sampled and submitted to TL analysis. Grouping individual dates by masonry enables us to decrease the uncertainty of the overall date, and so to obtain a more precise result. The same averaging from the masonry dates have been used to date the two phases.

This first comprehensive multidisciplinary study correlating archaeological and historical data with building material dating, will be completed later with the inclusion of archaeomagnetism dating also applied on bricks and $\mathrm{C} 14$ of charcoal present in mortars of the masonries in order to further improve the precision and the accuracy of dating the building phasing, and therefore, the understanding of the building process. This study will be developed on a number of other medieval buildings (churches, castles) in North-western France that present similar unanswered questions.

\section{Acknowledgements}

This research was supported by the CNRS, Department of Human and Social Sciences within the frame of the GdRE (Groupe de Recherche Européen) "Terres Cuites Architecturales et nouvelles méthodes de datation", University of Bordeaux 3, Conseil Régional d'Aquitaine, and the Direction Régionale des Affaires Culturelles-Service Régional de l'Archéologie de Basse-Normandie. Acknowledgements to Sandra Chabot and Pierre Verhaeghe, students of the universities of Bordeaux 1 and Bordeaux 3, respectively. Special thanks to Chris Simpson and Scott Grainger for the English review and to François Saint-James for his enthusiastic visit of 'unknown' parts of the Mont-Saint-Michel.

\section{References}

Adamiec, G., Aitken, M.J., 1998. Dose rate conversion factors: updatte, Ancient TL 16 (2), 37-50.

Aitken, M.J., 1985. Thermoluminescence Dating. Academic Press, London.
Bailif, I.K., Holland, N., 2000. Dating bricks of the two last millennia from Newcastle upon Tyne: a preliminary study. Radiat. Meas. 32, 615-619.

Baylé, M., 1997. La brique dans l'architecture préromane et romane de Normandie'. In: Medieval Archaeology, Brugge 97, Congrès international, Bruges, 1997, T.7.

Baylé, M., 2000. Norman architecture towards the year 1000. In: Proceedings of the Battle Conference (Anglo-Norman Studies), 1999, Woodbridge.

de Boüard, M., 1961. L'église Notre-Dame-Sous-Terre au Mont-Saint-Michel: essai de datation. J. des Savants, 10-27.

de Boüard, M., 1975. Manuel d'archéologie médiévale: de la fouille à l'histoire, Paris, 340p.

Brennan, B.J., Lyons, R.G., Phillips, S.W., 1991. Attenuation of alpha particle track dose for spherical grains. Radiat. Meas. 18, 249-253.

C.E.A., 1978. Statistiques appliquées aux mesures. Editions, Masson.

Faı"n, J., Miallier, D., Montret, M., Pilleyre, Th., Sanzell, S., Soumana, S., Bechtel, F., Guibert, P., Schvoerer, M., Vartagnian, E., Mercier, N., Valladas, H., Bahain, J.J., Falguères, C., Tripier, J., Joron, J.L., 1997. Intercomparaisons dosimétriques dans le cadre de la datation par TL et RPE, Partie 2: Milieux naturels témoins de la région de Clermont-Ferrand (Puy de Dôme). Revue d'Archéométrie 21, 29-34.

Froidevaux, Y.M., 1961. L'église Notre-Dame-sous-Terre de l'abbaye du Mont-Saint-Michel. Les Monuments Historiques de la France, 145-166.

Gallo, N., Fieni, L., Martini, M., Sibillia, E., 1999. Building archaeology, 14C and thermoluminescence: two examples comparison, Actes du Colloque, "C14 et Archéologie", III ${ }^{e}$ Congrès International, Lyon 6-10 avril 1998, Mémoire de Société préhistorique Française, tome XXVI et Supplément de la revue d'Archéométrie, pp. 425-431.

Guibert, P., 2002. Datation par luminescence des archéomatériaux: recherche méthodologiques et appliquées en archéologie médiévale et archéologie préhistorique; progrès récents et perspectives. Habilitation à diriger des recherches, Université de Bordeaux 3,

Guibert, P., Schvoerer, M., 1991. TL dating: low background gamma spectrometry as a tool for the determination of the annual dose. Nucl. Tracks Radiat. Meas. 18, 231-238.

Guibert, P., Vartanian, E., Bechtel, F., Schvoerer, M., 1996. Non-linear approach of TL response to dose: polynomial approximation. Ancien TL 14 (2), 7-14.

Guibert, P., Bechtel, F., Schvoerer, M., 1997. Déséquilibre des séries de l'uranium, implications sur la dose annuelle en datation par thermoluminescence: une étude à la Grotte XVI, Cénac et Julien, Dordogne (France). Quaternaire 8, 377-389.

Mejdahl, V., 1979. Thermoluminescence dating: beta-dose attenuation in quartz grains. Archaeometry 21, 61-72.

Roque, C., Vartagnian, E., Guibert, P., Schvoerer, M., Levine, D., Alva, W., Jungner, H., 2002. Recherche chronologique sur la culture Mochica du Pérou: datation de la Tombe du Prêtre de Sipan, par thermoluminescence (TL) et radiocarbone. Journal de la Société des Américanistes 88, 227-243.

Roque, C., Guibert, P., Dutine, M., Vartanian, E., Chapoulie, R., Bechtel, F., 2004. Dependence of luminescence characteristics of irradiated quartz with the thermal treatment and consequences for TL dating. Geochronometria $23,1-8$.

Sapin, C., 1997. Archéologie et monuments historiques: pour un langage commun. Archéologie des élévations dans les études et les travaux des Monuments Historiques. Fontevraud, Histoire et archéologie, vol. 4 (1995-1996) 2001, pp. 83-86.

Sapin, C., 2002. Archéologie de l'architecture carolingienne en France: état de la question. Hortus Artium medievalium, Zagreb-Motovun, pp. 57-70.

Vieillevigne, E., Guibert, P., Bechtel, F., Leriche, P., 2004. Thermoluminescence et chronologie du bâti médiéval: datation de briques de la citadelle de Termez en Ouzbékistan. Revue d'Archéométrie 28, 43-55.

Vieillevigne, E., Guibert, P., Zuccarello, A.R., Bechtel, F., 2006. The potential of optically stimulated luminescence for medieval building; a case study at Termez (Uzbekistan). Radiat. Meas. 41, 991-994. 